bệnh viện Bình Dân". Tap chíY hoc Việt Nam. Tập 319, 2/2006. Tr 254-261.

7. Abeshouse B. S. và Tankin L. H. (2012), Retrocaval ureter: Report of a case and a review of the literature, The American Journal of Surgery,
84(4), 383-393.

8. Cheung MC, Lee F, Yip SKH, Tam PC (2001). Outpatient holmium laser lithitripsy using semirigid ureteroscope: is the treatment outcome affected by stone load? Eur Urol; 39: 702-708

\title{
TÁC ĐộNG CỦA BẠO HÀNH TẠI NƠ'I LÀM VIÊCC ĐỐI VỚI HỌC VIÊN ĐIỀU DƯỡNG TẠI TRƯỜNG ĐẠI HỌC Y DƯỢC THÁI NGUYÊN
}

\section{TÓM TẮT}

Đặt vấn đề: Bạo hành tại bệnh viện đang ngày càng phổ biến, trong đó điều dưỡng là nhóm thường bi bạo hành vì phải trực tiếp, thường xuyên tiếp xúc với người bệnh. Nghiên cứu này được tiến hành nhằm muc tiêu: mô tả các tác đông của bao hành y tế đối với điều dưỡng viên. Đối tượng và phương pháp nghiên cứu: Nghiên cứu mô tả cắt ngang được thực hiện từ tháng 3 đến tháng 5 năm 2021. Hai trằm linh mồt học viên của các khóa hơc chuẩn hóa chức danh nghề nghiệp tại khoa điều dưỡng, trường Đại học $Y$ Dược Thái Nguyên được chọn thuận tiên vào nghiên cứu. Bốn mươi học viên báo cáo là đã̃ từng bị bạo hành. Các đối tượng này được phát vấn thông qua bộ câu hỏi tự điền về tình trạng của họ sau khi bị tấn công. Kết quả: Đối tượng gặp bạo hành y tế đa số là nữ giới, tuổi từ 30 đến dưới 40 tuổi, chủ yếu ở các khoa nội trú, khoa cấp cứu và phòng khám. Sau khi bị tấn công, $90 \%$ điều dưỡng cảm thấy lo lắng về tình trạng bạo hành tại nơi làm việc. Cảm nhận của điều dưỡng sau khi bị bạo hành đó là thường xuyên nhớ lại lúc bị tấn công $(87,5 \%)$, lo sợ mình lại bị tấn công trong tương lai $(90 \%)$, cực kỳ cảnh giác, chuẩn bị phòng vệ trong lúc làm việc $(90 \%)$, có cảm giác không yêu nghể như xưa $(75 \%)$, và ho ước mình đã đước đào tạo về phòng tránh bạo hành tại nơi làm việc $(95 \%)$. Kết luâan: Hầu hết điều dưỡng viên sau khi trải qua bao hành y tế đều cảm thấy lo lắng và thường xuyên nhớ lại lúc bi tấn công. Điều này khiến cho họ cảm thấy lo sợ và luôn cảnh giác, làm họ giảm đi sự gắn kết và yêu nghề. Mong muốn của họ là được đào tạo về phòng tránh bạo hành tại nơi làm việc.

Tư khóa: Bạo hành nơi làm việc, Điều dưỡng.

\section{SUMMARY}

THE IMPACT OF WORKPLACE VIOLENCE ON NURSING STUDENTS AT THAI NGUYEN UNIVERSITY OF MEDICINE AND PHARMACY

Background: Workplace violence in hospitals is increasing every year, in which nurses are especially

\footnotetext{
${ }^{1}$ Viện Khoa học Sức khoẻ, Trường Đại học VinUni

${ }^{2}$ Trường $\oplus H$ Y Dược Thái Nguyên

Chịu trách nhiệm chính: Nguyễn Hoàng Long

Email: long.nh@vinuni.edu.vn

Ngày nhân bài: 5.8.2021

Ngày phản biện khoa học: 6.10 .2021

Ngày duyệt bài: 13.10.2021
}

\section{Nguyễn Hoàng Long ${ }^{1}$, Ngô Xuân Long ${ }^{2}$}

vulnerable to violence and other forms of aggression in the workplace. To clarify this issue, we conducted this study to describe the impact of workplace violence on nurses. Methods: A cross-sectional was carried out from March to May, 2021. 201 nursing students at Thai Nguyen University of Medicine and Pharmacy are conveniently selected, in which 40 of them who experienced workplace violence were asked by the self-administered questionnaire about their status after being attacked. Results: The majority of victims of workplace violence are women aged from 30 to under 40 years old, mainly in inpatient departments, emergency departments and medical examination department. After being attacked, $90 \%$ of the nurses felt anxious with an avarage score of $6.70 \pm 2.79$. Nurses' feelings after experiencing violence are often recalling the time of being attacked $(87.5 \%)$, afraid of being get attacked again in the future $(90 \%)$, are extremely wary and defend themself from violence at work $(90 \%)$, do not love their job as before $(75 \%)$, and wishing that they had been trained on preventing violence $(95 \%)$. Conclusions: Most of nursing students after experiencing workplace violence feel anxiety, and they often recall the time of being assaulted. They are wary and do not love their job as before. So they wish they had been trained in workplace violence prevention.

Keywords: Workplace violence, Nurse.

\section{I. ĐẶT VẤN ĐỀ}

Do tính chất công việc và thời gian tiếp xúc bệnh nhân nhiêuu, điều dưỡng viên là một trong những đối tượng có nguy cơ cao gặp phải các tình huống bạo hành tại nơi làm việc.-Nghiên cứu của Groenewold và cộng sự (2017) về tình trạng bạo hành ở nơi làm việc giai đoạn 2012-2015 tại Mỹ cho thấy, điều dưỡng viên là đối tượng có nguy cơ bị bạo hành y tế cao gấp 1,7 lần so với các nhóm nhân viên y tế khác [3]. Tổng quan 136 nghiên cứu quốc tế tại Anh, châu Á, châu Âu và khu vực Trung Đông của Spector và cộng sự (2014) cho thây, có 36,4\% điều dưỡng cho biết họ đã bị tấn công, với $67,2 \%$ trường hợp báo cáo về các vụ tấn công phi vật lý [5]. Nghiên cứu của Pinar và Ucmark (2011) về bạo hành lời nói và thể chất đối với điều dưỡng tại các khoa cấp cứu ở Istanbul Thổ Nhĩ Kỳ cũng chỉ ra rằng 
$74,9 \%$ điều dưỡng trải qua bạo hành thể chất ít nhất 1 vài đợt trong 12 tháng trước đó, với tỷ lệ bạo hành bằng lời nói là $91,4 \%$ [4]. Tại Việt Nam, nghiên cứu của Đào Ngọc Phức (2017) tại bệnh viện Nhi Trung ương cho thây $72,7 \%$ điều dưỡng bị bạo hành trong 12 tháng qua; 65,3\% điều dưỡng bị bạo hành lời nói và $23,7 \%$ điều dưỡng bị bạo hành thể chất [2].

Shu-E Zhang và cộng sự đã chỉ ra rằng việc đối mặt với bạo hành khiến 83,33\% điêuu dưỡng viên bị giảm chất lượng giấc ngủ, các tình huống bạo hành khiến họ cảm thây không an toàn, lo âu và trầm cảm, gây ảnh hưởng không tốt đến chất lượng cuộc sống và công việc của họ [7]. Như vậy bạo hành nơi làm việc có ảnh hưởng rất lớn đến sức khỏe thể chất và tinh thần của điều dưỡng viên, gián tiếp ảnh hưởng đến hiệu quả chăm sóc điều trị cho bệnh nhân. Tại Việt Nam, một số nghiên cứu về bạo hành tại bệnh viện đối với nhân viên y tế và điều dưỡng đã được thực hiện, tuy nhiên mới dừng lại ở mức độ mô tả thực trạng. Chưa có nghiên cứu nào đánh giá các tác động của bạo hành tại nơi làm việc đối với điều dưỡng viên. Chính vì vậy chúng tổi tiến hành nghiên cứu này nhằm: mô tả tác động của bạo hành trong các cơ sở y tế đối với điều dưỡng viên. Kết quả của nghiên cứu sẽ giúp các nhà quản lý đánh giá sâu hơn về những ảnh hưởng tiêu cực liên quan đến bạo hành tại nơi làm việc mà các điêu dưỡng viên phải trải qua, từ đó có những giải pháp kịp thời để giải quyết vấn đề này.

\section{II. ĐỐI TƯỢNG VÀ PHƯƠNG PHÁP NGHIÊN CỨU}

2.1 Thiết kế nghiên cứu: Nghiên cứu mô tả cắt ngang

2.2. Địa điểm, thời gian, đối tượng nghiên cứu: Nghiên cứu được tiến hành từ tháng 3 đến tháng 5 năm 2021. Đối tượng nghiên cứu là các học viên vừa làm vừa học và học viên khóa chuẩn hóa chức danh nghề nghiệp của Khoa Điều dưỡng, Trường đại học $Y$ Dược Thái Nguyên.

2.3. Cõ̃ mẫu và phương pháp chọn mẫu: Đối tượng tham gia nghiên cứu là 40 điểu dưỡng viên báo cáo là đã từng bị bạo hành tại nơi làm việc trong số 201 học viên tham gia khảo sát về thực trạng bạo hành tại nơi làm việc. Mẫu nghiên cứu được chọn lựa bằng phương pháp chọn mẫu thuân tiện.

2.4. Phương pháp thu thâp thông tin: Phát vấn đối tượng, sử dụng bộ cẩu hỏi tự điền.

2.5. Bộ công cụ và thang đo: Bộ công cụ được nhóm nghiên cứu xây dựng dựa trên tổng quan tài liệu, có 3 nội dung cụ thể gồm thông tin chung, mức độ lo lắng của điều dưỡng và tình trạng của họ sau khi bị tấn công. Với mức độ lo lắng với tình trang bạo hành, nghiên cứu sử dụng thang đo từ 1-10 để đo lường, tương ứng với mức từ không lo lắng đến rất lo lắng. Các tình trang sau khi bị tấn công được lựa chọn dựa trên tổng quan các nghiên cứu đã công bố trền thế giới về trải nghiệm của điều dưỡng viên sau khi bị bạo hành, như việc nhớ lại sự kiện bị tấn công, giảm cảm giác yêu nghề, sợ tiếp tục bị tấn công trong tương lai...Với mỗi nội dung, đối tượng nghiên cứu trả lời trên thang đo gồm 5 mức, từ "không hê" đến "rất nhiều".

2.5. Phân tích số liệu: Phương pháp thống kê mô tả được sử dụng để tính toán tỷ lệ \%, giá trị trung bình và độ lệch chuẩn.

2.6. Đạo đức nghiên cứu: Nghiên cứu được thông qua bởi hội đồng đạo đức trong nghiên cứu y sinh của bệnh viện Trung ương Thái Nguyên.

\section{KẾT QUẢ NGHIÊN CỨU}

Bảng 1: Đặc điểm chung của đôi tượng nghiên cứu $(n=40)$

\begin{tabular}{|c|c|c|c|}
\hline \multicolumn{2}{|c|}{ Đăc điểm } & $\mathbf{n}$ & $\%$ \\
\hline \multirow{4}{*}{ Tuổi } & $<30$ & 5 & 12,5 \\
\hline & $30-<40$ & 31 & 77,5 \\
\hline & $40-<50$ & 4 & 10,0 \\
\hline & $\geq 50$ & 0 & 0,0 \\
\hline \multirow{2}{*}{ Giới } & Nam & 14 & 35,0 \\
\hline & Nữ & 26 & 65,0 \\
\hline \multirow{4}{*}{ Trình độ } & Trung cấp & 4 & 10,0 \\
\hline & Cao đằng & 17 & 42,5 \\
\hline & Đại học & 19 & 47,5 \\
\hline & Sau đai hoc & 0 & 0,0 \\
\hline \multirow{3}{*}{$\begin{array}{c}\text { Thời gian từ } \\
\text { khi tốt nghiệp } \\
\text { đến nay }\end{array}$} & 5 năm & 5 & 12,5 \\
\hline & 5-10 năm & 17 & 42,5 \\
\hline & Trên 10 năm & 18 & 45,0 \\
\hline \multirow{3}{*}{$\begin{array}{l}\text { Tình trang } \\
\text { hôn nhân }\end{array}$} & Chưa kết hôn & 7 & 17,5 \\
\hline & Đã kết hôn & 32 & 80,0 \\
\hline & Ly hôn/góa & 1 & 2,5 \\
\hline \multirow{4}{*}{$\begin{array}{l}\text { Đơn vị công } \\
\text { tác }\end{array}$} & Khoa nội trú & 17 & 42,5 \\
\hline & Khoa khám bênh & 4 & 10,0 \\
\hline & Khoa cấp cứu & 9 & 22,5 \\
\hline & $\begin{array}{c}\text { Phòng ban/cận lâm } \\
\text { sàng }\end{array}$ & 10 & 25,0 \\
\hline
\end{tabular}

Kết quả bảng trên cho thãy hơn một nửa đố tượng nghiên cứu là nữ giới với tỷ lệ $65 \%$, và độ tuổi của điều dưỡng chủ yếu từ 30 đến dưới 40 tuổi, chiếm 77,5\%. Đa phần đối tượng nghiên cứu có trình độ cao đẳng và đại học với tỷ lệ \% tương đương nhau (lần lượt là $42,5 \%$ và 47,5\%). Thời gian trung bình từ khi tốt nghiệp đến nay của điêu dưỡng là 10,32 năm $( \pm 4,35)$, 
trong đó thời gian tốt nghiệp ít nhất là 1 năm, lâu nhất là 21 năm. Đa số đối tượng nghiên cứu đã kết hôn (80\%) và gần một nửa đối tượng làm việc tại các khoa nội trú (42,5\%).

\section{Bảng 2: Tình trạng sau khi bị tấn công của điều dướng $(n=40)$}

\begin{tabular}{|c|c|c|c|c|c|}
\hline & Khồng hề & Một chút & Khá nhiều & Nhiều & Rất nhiều \\
\hline Thường xuyên nhớ lại lúc bị tấn công & $5(12,5 \%)$ & $17(42,5 \%)$ & $12(30,0 \%)$ & $5(12,5 \%)$ & $1(2,5 \%)$ \\
\hline $\begin{array}{c}\text { Cố tránh suy nghĩ hay nói chuyện về } \\
\text { viêc bi tấn công }\end{array}$ & $\begin{array}{c}10 \\
(25,0 \%)\end{array}$ & $\begin{array}{c}16 \\
(40,0 \%)\end{array}$ & $\begin{array}{c}10 \\
25,0 \%)\end{array}$ & $\begin{array}{c}3 \\
(7,5 \%)\end{array}$ & $\left(2, \frac{1}{5} \%\right)$ \\
\hline $\begin{array}{c}\text { Cực kỳ cảnh giác, chuấn bị phòng vệ } \\
\text { trong lúc làm việc }\end{array}$ & $\begin{array}{c}4 \\
(10,0 \%)\end{array}$ & $\begin{array}{c}16 \\
(40,0 \%)\end{array}$ & $\begin{array}{c}11 \\
(27,5 \%)\end{array}$ & $\begin{array}{c}8 \\
(20,0 \%)\end{array}$ & $\begin{array}{c}1 \\
(2,5 \%)\end{array}$ \\
\hline Có cảm giác không yêu nghề như xưa & $10(25,0 \%)$ & $18(45,0 \%)$ & $9(22,5 \%)$ & $1(2,5 \%)$ & $2(5,0 \%)$ \\
\hline Lo sợ mình lại bị tấn công trong tương lai & $4(10,0 \%)$ & $18(45,0 \%)$ & $10(25,0 \%)$ & $5(12,5 \%)$ & $3(7,5 \%)$ \\
\hline $\begin{array}{l}\text { Ước mình đã được đào tạo về phòng } \\
\text { tránh bạo hành nơi làm việc }\end{array}$ & $\begin{array}{c}2 \\
(5,0 \%)\end{array}$ & $\begin{array}{c}15 \\
(37,5 \%)\end{array}$ & $\begin{array}{c}6 \\
(15,0 \%)\end{array}$ & $\begin{array}{c}7 \\
17,5 \%)\end{array}$ & $\begin{array}{c}10 \\
(25,0 \%)\end{array}$ \\
\hline
\end{tabular}

Bảng 2 cho thấy, 87,5\% điều dưỡng viên thường xuyên nhớ lại lúc bị tấn công và $75 \%$ điều dưỡng viên cố tránh suy nghĩ hay nói chuyện về việc bị tấn công ở các mức độ khác nhau. Tương tự, có $90 \%$ điều dưỡng lo sợ mình lại bị tấn công trong tương lai. Đáng chú ý, tỷ lệ điều dưỡng viên trả lời rằng họ ước mình đã được đào tạo về phòng tránh bạo hành tại nơi làm việc ở 2 mức độ rất nhiều là $25 \%$ và nhiều là 17,5\%. Tổng số $75 \%$ điều dưỡng viên cho biết mình có cảm giác không yêu nghề như xưa ở các mức độ khác nhau, từ một chút tới rất nhiều.

Bảng 3: Mức độ lo lắng của điều dướng về bạo hành tại nơi làm việc $(n=40)$

\begin{tabular}{|c|c|c|}
\hline Mức độ lo lắng & $\mathbf{n}$ & $\mathbf{\%}$ \\
\hline $1-$ Không lo lắng & 4 & 10,0 \\
\hline 2 & 0 & 0,0 \\
\hline 3 & 2 & 5,0 \\
\hline 4 & 1 & 2,5 \\
\hline 5 & 2 & 5,0 \\
\hline 6 & 12 & 30,0 \\
\hline 7 & 2 & 5,0 \\
\hline 9 & 2 & 12,5 \\
\hline $10-$ Rất lo lắng & 10 & 5,0 \\
\hline Điếm trung bình & $6,70( \pm 2,79)$ \\
\hline
\end{tabular}

Bảng 3 cho thấy điểm trung bình mức độ lo lắng của điều dưỡng về tình trạng bạo hành tại nơi làm việc là $6,70( \pm 2,79)$. Đáng chú ý, tỷ lệ đối tượng cảm thây rất lo lắng (tương đương mức độ 10 ) là $25 \%$ và chỉ có $10 \%$ điều dưỡng là không có chút lo lắng nào.

\section{BÀN LUẬN}

Kết quả nghiên cứu cho thấy, $90 \%$ điều dưỡng đã từng bị bạo hành báo cáo rằng mình cảm thấy lo lắng về bạo hành tại nơi làm việc, và có tới $25 \%$ số người được hỏi chọn mức độ lo lắng tối đa $10 / 10$ điểm. Kết quả này tương đồng với kết quả nghiên cứu của tác giả Đào Ngọc Phức (2017) tại viện Nhi TW, rằng 92,7\% điều dưỡng cảm thấy lo lắng sau khi bị bạo hành [2]. Đáng chú ý, kết quả nghiên cứu cũng chỉ ra $90 \%$ điều dưỡng cho biết họ cực kỳ cảnh giác, chuẩn bị phòng vệ trong lúc làm việc. Điều này cho thấy, điều dưỡng viên đang có tâm trạng bất an sau khi bị bạo hành và rất cần được quan tâm để yên tâm công tác. Bên cạnh đó, có $87,5 \%$ điều dưỡng thường xuyên nhớ lại lúc bị tấn công, $75 \%$ điều dưỡng cố tránh suy nghĩ hay nói chuyện về việc bị tấn công. Đây là trạng thái tâm lý đối lập của đối tượng nghiên cứu: họ cố lảng tránh, chạy trốn khỏi ký ức về việc bị bạo hành nhưng lại thường xuyên nhớ lại nó.

Nhiều nghiên cứu khác công bố trên thế giới chỉ ra rất nhiều tác động tiêu cực của bạo hành tại nơi làm việc. Nghiên cứu của Pinar và Ucmark (2011) về bạo hành lời nói và thể chất đối với điều dưỡng tại các khoa cấp cứu ở Istanbul Thổ Nhĩ Kỳ chỉ ra rằng, sau khi trải qua bạo hành hầu hết các điêuu dưỡng đều cảm thấy sợ hãi, $65 \%$ điều dưỡng cảm thấy không an toàn trong các khoa cấp cứu, $3 \%$ điều dưỡng cho biết họ xin nghỉ ốm, trong đó $80 \%$ tránh hoặc không báo cáo về tình trạng bạo hành mà họ gặp phải [4]. Cũng tương tự, nghiên cứu Yuan Jang và cộng sự (2021) cho biết những điều dưỡng sau khi bị bạo hành y tế thì xuất hiện các triệu chứng lo âu, trầm cảm và mất ngủ nhiều hơn, đồng thời điểm chất lượng cuộc sống của họ cũng thấp hơn $(p<0,001)$ [6]. Nghiên cứu của Đào Ngọc Phức viện Nhi TW (2017) cũng chỉ ra sau khi trải qua bạo hành có $89,4 \%$ điêu dưỡng bị stress, $92,7 \%$ cảm thấy lo lắng [2]. Kết quả từ nghiên cứu này và các nghiên cứu khác cho thây điêuu dưỡng viên rất cần được hỗ trợ về tâm lý và thể chất sau bạo hành để có thể quên đi và vượt qua một trải nghiệm nghề nghiệp rất không tốt, trở lại với cuộc sống cũng như công việc thường ngày.

Đáng chú ý, có $75 \%$ điêu dưỡng viên cho biết mình có có cảm giác không yêu nghề như xưa. 
Tương tự, nghiên cứu của Đào Ngọc Phức (2017) tại viện Nhi TW cho thây $26,6 \%$ điều dưỡng sau khi bị bạo hành y tế muốn thay đổi nơi làm việc, $76,1 \%$ giảm hiệu suất làm việc [2]. Do đó, các bệnh viện cần có các sinh hoạt nghề nghiệp phù hợp, giúp các đối tượng đã bị bạo hành duy trì và nâng cao tình yêu nghề nghiệp, tránh tình trang bỏ nghề sau khi bị bạo hành. Bên cạnh đó, nghiên cứu của Đỗ Mạnh Hùng (2018) chỉ ra rằng mối quan hệ không tốt với người bệnh và người nhà người bệnh là yếu tố nguy cơ bị bạo hành ở điều dưỡng viên $(p<$ 0,01)[1]. Trong nghiên cứu này, $95 \%$ điều dưỡng viên trả lời họ ước mình đã được đào tạo về phòng tránh bạo hành tại nơi làm việc. Như vậy, việc tập huấn, đào tạo các kỹ năng để xây dựng mối quan hệ với người bệnh cũng như phòng tránh bạo hành cho điều dưỡng viên có thể là biện pháp can thiệp hữu ích giúp giảm bạo hành tại khoa phòng.

\section{KẾT LUÂ̂N}

Sau khi bị tấn công, 90\% điều dưỡng viên cảm thấy lo lắng về tình trạng bạo hành tại nơi làm việc. Bên cạnh đó, tác động của trải nghiệm bạo hành tại nới làm việc tới điều dưỡng viên bao gồm: Thường xuyên nhớ lại lúc bị tấn công $(87,5 \%)$; Cố tránh suy nghĩ hay nói chuyện về việc bị tấn công (75\%); Lo sợ mình lại bị tấn công trong tương lai (90\%); Cực kỳ cảnh giác, chuẩn bị phòng vệ trong lúc làm việc $(90 \%)$; Có cảm giác không yêu nghề như xưa $(75 \%)$; Uớc mình đã được đào tạo về phòng tránh bạo hành tại nơi làm việc (95\%).

\section{TÀI LIÊU THAM KHẢO}

1. Đỗ Mạnh Hùng, Lưu Thị Mỹ Thục, Phạm Thu Hiên (2018). Môt số yếu tố ảnh hưởng đến bao hành nơi làm việc bằng lời nói do khách hàng gầy ra đố với điều dưỡng viên tại các khoa lâm sang bệnh viện Nhi TW. Tạp chí Y học thành phố Hồ Chí Minh, 22(6).

2. Đào Ngoc Phức. Thực trang bao hành bênh viện đối với đ̛uêuu dưỡng viên và một số yếu tố ảnh hưởng tại bệnh viện Nhi Trung ương năm 2017. Luận văn thạc sỹ quản lý bệnh viện, Đại học Y tế công cộng.

3. Groenewold, M. R., Sarmiento, R. F. R., Vanoli, K., Raudabaugh, W., Nowlin, S., \& Gomaa, A. (2017). Workplace violence injury in 106 US hospitals participating in the occupational health safety network (OHSN), 2012-2015. American Journal of Industrial Medicine, 61(2) 157-166

4. Rukiye Pinar, Firdevs Ucmak (2011). Verbal and physical violence in emergency departments: a survey of nurses in Istanbul, Turkey. Journal of clinical nursing, 20(3-4):510-7

5. Spector, P. E., Zhou, Z. E., \& Che, X. X. (2014). Nurse exposure to physical and nonphysical violence, bullying, and sexual harassment: A quantitative review. International Journal of Nursing Studies, 51(1), 72-84.

6. Yuan Yang, et.al, Workplace Violence Against Chinese Frontline Clinicians During the COVID-19 Pandemic and Its Associations With Demographic and Clinical Characteristics and Quality of Life: A Structural Equation Modeling Investigation. Front Psychiatry. 2021; 12: 649989.

7. Zhang S, Liu ' $\mathbf{W}$, Wang $\mathbf{J}$, et al. Impact of workplace violence and compassionate behaviour in hospitals on stress, sleep quality and subjective health status among Chinese nurses: a crosssectional survey BMJ Open 2018;8: e019373. doi: 10.1136/bmjopen-2017-019373.

\section{KẾT QUẢ CHĂM SÓC NGƯờI BÊNH SAU MỔ GÃY XƯƠNG CHI DƯỚI TẠI KHOA NGOẠI BỆNH VIỆN TRUNG ƯO'NG THÁI NGUYÊN}

\section{Mai Thị Vân Hằng ${ }^{1}$, Nguyễn Đình Phúc ${ }^{2}$, Lê Hải Yến ${ }^{1}$}

\section{TÓM TẮT}

Mục tiêu: Đánh giá kết quả chăm sóc người bệnh (NB) sau mổ gãy gãy xương chi dưới tại khoa ngoại bệnh viện Trựng ương Thái Nguyên. Đối tượng: 166 NB được phẫu thuật gãy xương đùi và xưởng cẳng chân tại khoa Ngoai chấn thương chỉnh hình bênh viên Trung Ương Thái Nguyên từ tháng 10 năm 2020 đến

${ }^{1}$ Trường Cao đẳng Y tế Thái Nguyên
${ }^{2}$ Trường Đại hoc Thăng Long Hà Nội.

Chịu trách nhiệm chính: Mai Thị Vân Hằng

Email: vanhang119@gmail.com

Ngày nhận bài: 6.8.2021

Ngày phản biên khoa hoc: 4.10 .2021

Ngày duyệt bài: 13.10 .2021 tháng 04 năm 2021. Kết quả: Nguyên nhân gãy xương do tai nạn giao thông chiếm 72,9 \%, gãy kín chiếm $71,1 \%$. Gã̃y thân hai xương cẳng chân chiếm tỷ lệ 38,6\%. Trong 24 giờ đầu sau mổ, đau vừa $68,7 \%$, đau nhiều chỉ chiếm 19,2\%. Thời điểm ra viện các mức độ đau giảm dần. Tình trang vết mổ khô bình thường chiếm 98,2\% Người bệnh ăn uống bình thường $(97,0 \%)$, được tập nhẹ các ngón chân $(98,8 \%)$. Kết quả chăm sóc NB sau mổ, tâi thời điểm 24h có $96,3 \%$ Người bệnh có tình trạng phẫu thuật tốt chiếm 93,3\%. Không có trường hợp nào có tình trạng xấu sau phấu thuật

Tư khóa: gãy xương, chi dưới, gãy xương chi dưới, khoa ngoại, bệnh viện.

\section{SUMMARY}

